\title{
Verification of a Synchronous Machine Model for Stator Ground Fault Simulation Through Measurements in a Large Generator
}

\author{
A. Bermejo, C.A. Platero, F. Blázquez, F. Blánquez and E. Rebollo
}

\section{INTRODUCTION}

Power systems must use protection relays in order to safeguard them against abnonnal operations as short circuits, overloads and, in general any fault that could damage the facilities and the power plant staff.

One of the most common electrical defects on power synchronous generators is the stator grotuld fault [1]. The synchronous machine is the most usual machine used as generator and it is committed to provide unintempted power to a lot of consumers, for this reason, its reliability is crucial.

The effect of a ground-fault depends highly on the method its neutral is grounded [2]. Large generators usually are grounded through a high value resistor. The value of this resistor makes the maximum ground fault current to be set between 5 and $10 \mathrm{~A} \mathrm{[3].} \mathrm{At} \mathrm{these} \mathrm{limited} \mathrm{values} \mathrm{of} \mathrm{ground}$ fault, the damage at the machine iron core is insignificant, however it makes the fault much difficult to locate.

The traditional way to protect the synchronous generators against stator ground faults, is an over-voltage relay installed in the grounding resistor (59N). This relay is tuned to the fundamental frequency, so it is not sensible to any other harmonics. It can protect between $90-95 \%$ of the winding, but still a $5-10 \%$ of the winding close to neutral end is not protected. A similar solution is the use of an overcurrent relay $(51 \mathrm{~N})$.

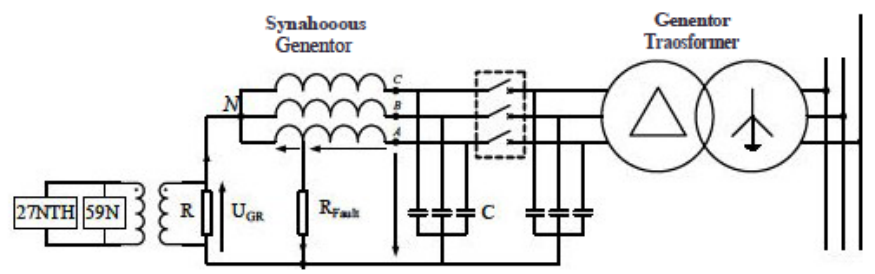

Figure 1. Simplified generator $59 \mathrm{~N}$ and $27 \mathrm{NTH}$ protection layout.
Most of the generators were protected against ground faults only with the above protections having a. part of the windings unprotected.

It was thought that a fault in that unprotected portion would not produce significant damage, as the fault current would be very small, however the experience has shown just the opposite.

If a first fault takes place and it is not remove, the next ground fault will be a phase to phase fault, the consequences of this second fault would involve catastrophic for the machine [3]-[4].

As a result of these considerations and the development of different relay technology, several $100 \%$ winding protection schemes are now available. They fall into two categories: third harmonic voltage schemes [5]-[6] and neutral injection schemes [7].

\section{A. Third Harmonic Schemes}

Generator's output voltage is not a. perfect sinusoidal wave and all machines produce voltages harmonics. The third harmonic voltage is one of them and it is used for ground fault detection.

The third harmonic method is based on the presence of a. third harmonic voltage under healthy condition of the generator grounding resistor. In case of a ground fault in the winding close to the neutral terminal, the third harmonic voltage will be reduced notably, being zero if the fault takes place in the neutral with no fault resistance.

Therefore by the use of ailtulder-voltage relay (27NTH), which measures the third harmonic voltage at the neutral of the machine, the first part of the winding (5-10\%) could be protected. To make the $100 \%$ stator ground fault protection effective, this relay must be overlapped with the $59 \mathrm{~N}$ relay, previously described. 
When a stator ground fault occurs near the neutral, the third harmonic voltage becomes zero at the exact point where the defect takes place. The third harmonic at the neutral resistor decreases and at the generator terminals increases. [8].

It is important to take into account that when a ground fault occurs, the fault position and the fault resistance are parameters which influence significantly in the third harmonic measured in the generator grounding resistor.

Another important factor is the percentage of third harmonic produce by the generator.

The third harmonic voltage produced by the generator is critical to the successful operation of this protection relay. The magnitude of this component depends on the operating conditions of the generator [9]-[11].

In order to avoid the inappropriate operation of $27 \mathrm{NTH}$ relay is a common practice to block it during the start-up process, as well as during low active or reactive power operating conditions, as in these conditions the third harmonic is very low and the under-voltage relay could produce a false trip.

Another method based on the third harmonic study is the third harmonic overvoltage scheme.

It incorporates the same principles introduced with the under-voltage scheme. In this application, an open delta PT connection is used to detect zero-sequence voltage at the generator terminals.

The overvoltage relay is tuned to the third harmonic voltage and operates if the third harmonic voltage rises over a certain threshold at the generator terminals.

Finally the last technique based on the evolution of the third harmonic along the stator winding is the ratio scheme.

In this scheme, the impedances of the zero sequence circuit theoretically fix the ratio of third harmonic terminal voltage and at the neutral during normal operation. When a ground fault occurs in the stator winding, this ratio is altered.

The voltage ratio scheme uses this change in the ratio to detect ground faults at the neutral and at the terminals end of the stator winding. This scheme, as the others two, includes the $59 \mathrm{~N}$ overvoltage relay to provide full protection all along the winding.

\section{B. Neutral Injection Scheme (64S)}

As it was explained before, the third harmonic techniques need that the machine could produce enough third harmonic to be effective. As consequence of this limitation, another extended solution is the low-frequency injection scheme (64S) [12].

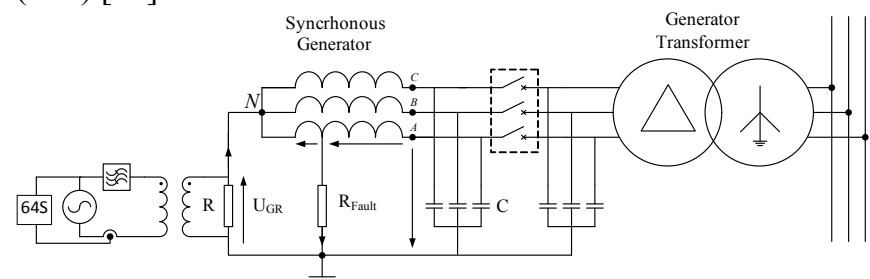

Figure 2. Simplified generator $64 \mathrm{~S}$ protection layout
It is based on the injection of a low-frequency voltage signal $(12.5,15$ or $20 \mathrm{~Hz}$ are the most common values used in the grounding impedance through a band-pass filter). This protection obtains the equivalent impedance by measuring the low- frequency current, which changes during ground faults. This technique is more expensive that the third harmonic scheme explained above, nevertheless no unwanted trips are produced.

To calculate in a precise way the first and third harmonics in the grounding resistor a synchronous machine model is required.

The common synchronous machine models do not allow simulating internal ground faults.

In this paper a simple synchronous machine model for internal ground fault simulation is presented.

The model is validated for healthy condition operation through the measurement taken in a large hydro generator.

\section{MeASUREMENTS IN A 106 MVA SynCHRONOUS GENERATOR}

Before the development of the model, numerous measurements were taken on a 106 MVA hydro generator installed in a four unit's pumped storage hydro power plant.

The neutral to ground voltage $\mathrm{U}_{\mathrm{NG}}$ and the phase to ground voltage $\mathrm{U}_{\mathrm{PG}}$ were recorded with an oscilloscope during normal operation of the generator at different active and reactive loads. With these data, the precise third harmonic voltage produced by the generator can be calculated as follow.

Firstly in other to obtain the voltage in the generator stator winding $\mathrm{U}_{\mathrm{GN}}$ the voltage $\mathrm{U}_{\mathrm{PG}}$ and the voltage $\mathrm{U}_{\mathrm{NG}}$ should be subtracted. (See fig. 5)

Afterward the Fast Fourier Transform (FFT) should be applied to the $\mathrm{U}_{\mathrm{GN}}$, and the component with three times the network frequency should be taken, in this case $150 \mathrm{~Hz}$.

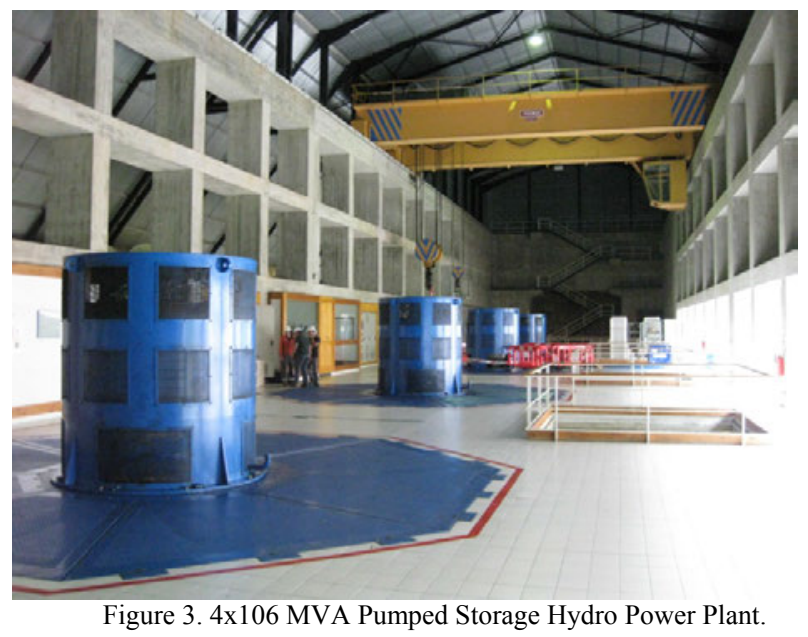


TABLE I. CHARACTERISTICS OF THE 106 MVA SYNCHRONOUS MACHINE CHARACTERISTICS OF THE 106 MVA SYNCHRONOUS MACHINE

\begin{tabular}{|c|c|c|}
\hline Rated apparent power & 106 & MVA \\
\hline Rated Power Factor & 0.8 & \\
\hline Rated voltage $( \pm 5,0 \%)$ & 12 & $\mathrm{kV}$ \\
\hline Frequency & 50 & $\mathrm{~Hz}$ \\
\hline Rated speed & 500 & $\mathrm{rpm}$ \\
\hline s synchronous reactance (unsat) $X_{d}$ & 1.05 & $\mathrm{pu}$ \\
\hline are-axis synchronous reactance $X_{q}$ & 0.70 & $\mathrm{pu}$ \\
\hline s subtransient reactance (unsat) $X_{d}^{\prime}$ & 0.26 & $\mathrm{pu}$ \\
\hline s subtransient reactance (unsat) $X{ }_{d}$ & 0.19 & $\mathrm{pu}$ \\
\hline re-axis subtransient reactance $X^{\prime \prime}{ }_{q}$ & 0.19 & $\mathrm{pu}$ \\
\hline ansient open-circuit time constant $T_{d o}^{\prime}$ & 9.5 & $\mathrm{~s}$ \\
\hline ransient short-circuit time constant $T_{d}^{\prime}$ & 1.6 & $\mathrm{~s}$ \\
\hline abtransient short-circuit time const $T$ "' ${ }_{d}$ & 32 & $\mathrm{~ms}$ \\
\hline Rated field current $I_{f n}$ & 1060 & A \\
\hline Rated field voltage $U_{f n}$ & 241 & $\mathrm{~V}$ \\
\hline
\end{tabular}

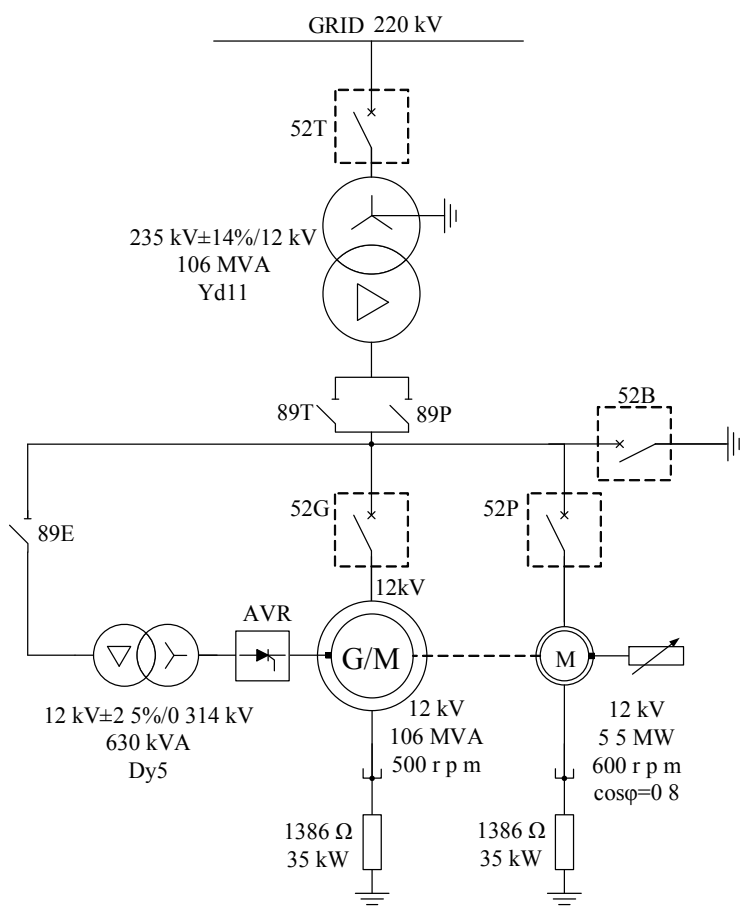

Figure 4. Single line diagram of the 106 MVA generator.

More than forty different measurements were analyzed during this work. As an example of one of these measurements is represented in the fig. 6 with the generator at $85 \mathrm{MW}$ and 10 Mvar.

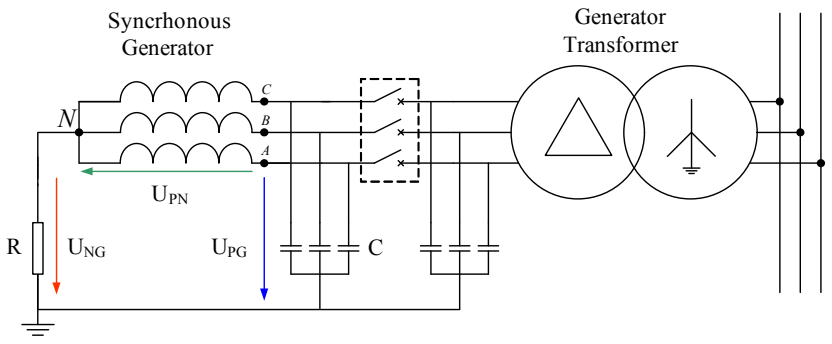

Figure 3. Voltages measured $U_{\mathrm{PG}}$ and $\mathrm{U}_{\mathrm{NG}}$ and voltage calculated $\mathrm{U}_{\mathrm{PN}}$ at the106 MVA generator.

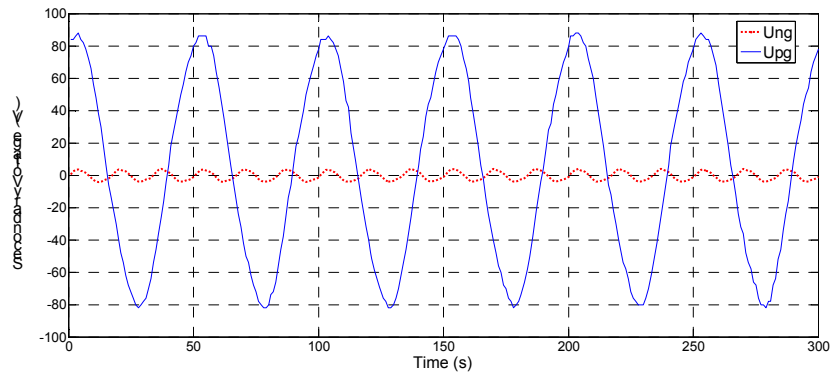

Figure 4. Voltages $\mathrm{U}_{\mathrm{PG}}$ and $\mathrm{U}_{\mathrm{NG}}$ measured at the106 MVA generator (85 MW and 10 Mvar)

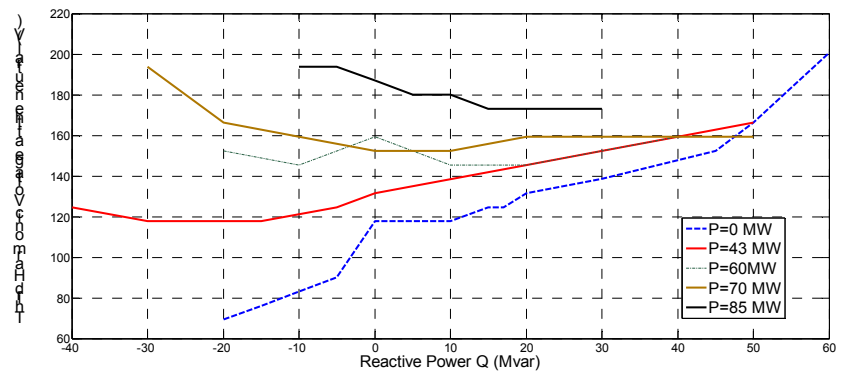

Figure 5. Third harmonics voltage in the 106 MVA generator for different operation points

\section{Synchronous Generator Model}

There are two main scenarios to analyze: the first one is when the generator is operating under normal conditions and the second when a stator-ground-fault takes place at some point along the stator winding.

\section{A. Generator model under non-fault conditions.}

This model represents the effects of the third harmonic voltage by a $150 \mathrm{~Hz}$ AC source (E1 $150 \mathrm{~Hz})$. Also a $50 \mathrm{~Hz}$ AC source is considered (E1 $50 \mathrm{~Hz})$. As a three phase machine, all these sources are located all along each phase which the correspondence phase-shift.

The generator capacitance $\mathrm{C}_{\mathrm{g}}$ is distributed uniformly and constant along the stator winding and it will be modeled with two capacitors of $\mathrm{C}_{\mathrm{g}} / 2$. One of them will be placed at the neutral point and the other one at the beginning of the winding. In other to consider the capacitances of the bus-bar and the generator transformer a $\mathrm{C}_{\mathrm{p}}$ capacitance will be considered at the generator terminals.

The series inductance of the windings is neglected as its value is insignificant if it is compared to the grounding resistor $\mathrm{R}$.

The model is based on this simplified scheme. It is developed by SimPowerSystem ${ }^{\circledR}$ Simulink ${ }^{\circledR}$ software.

Apart from the elements exposed in the scheme above, in the model there are also measurements blocks, FFT blocks to separate the third harmonic voltage and the voltage at fundamental frequency at the neutral of the machine. It is 
important to verify the correct operation of the model, which will be explained in the next section.

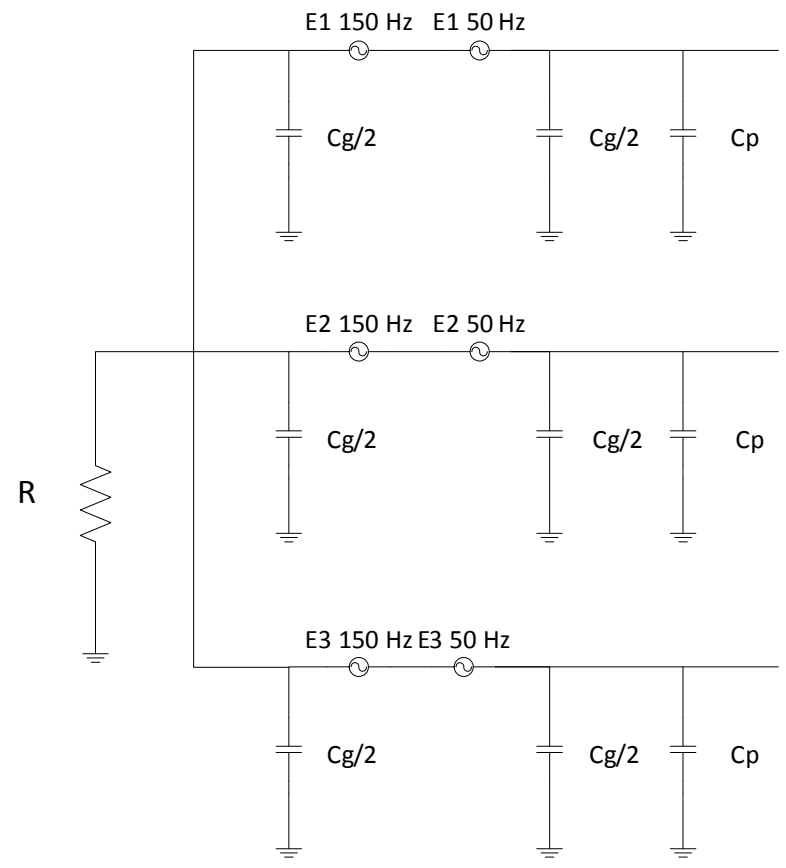

Figure 6. Generator model under normal operation conditions.

\section{B. Generator Model under fault conditions}

The two non-faulted phases have the same scheme as the above model. On the other hand for the faulted phase instead of having just two AC sources as in the healthy phases, there are four AC sources. From the neutral end to the point of the winding where the fault takes place, there are one $150 \mathrm{~Hz}$ $\mathrm{AC}$ source and a $50 \mathrm{AC}$ source. From the point where the fault takes place to the generator terminals, there are the other two AC sources. Again there is one source of $150 \mathrm{~Hz}$ of frequency and the other one at $50 \mathrm{~Hz}$. The value of each source depends directly with the location of the fault.

More specifically they are function of the distance from the neutral to where the fault takes place.

Another parameter which also changes its value according to the location of the fault is the generator's capacitance to ground.

The last variable which has to be introduced in this scheme is the fault resistance. This parameter is located at the exact point where the fault takes place and depending of its value the measurements of the third harmonic at the neutral could change significantly.

\section{VERIFICATION OF THE MODEL}

After the model description, the next step is to verify that these models operate according to the circumstances considered. The generator model under non fault conditions will be verified first and then, the model under fault conditions.
First of all the calculation of the phase-ground voltage has to be done. It will be achieved subtracting the neutralground data of the phase-ground data from the measurements at the 106 MVA generator.

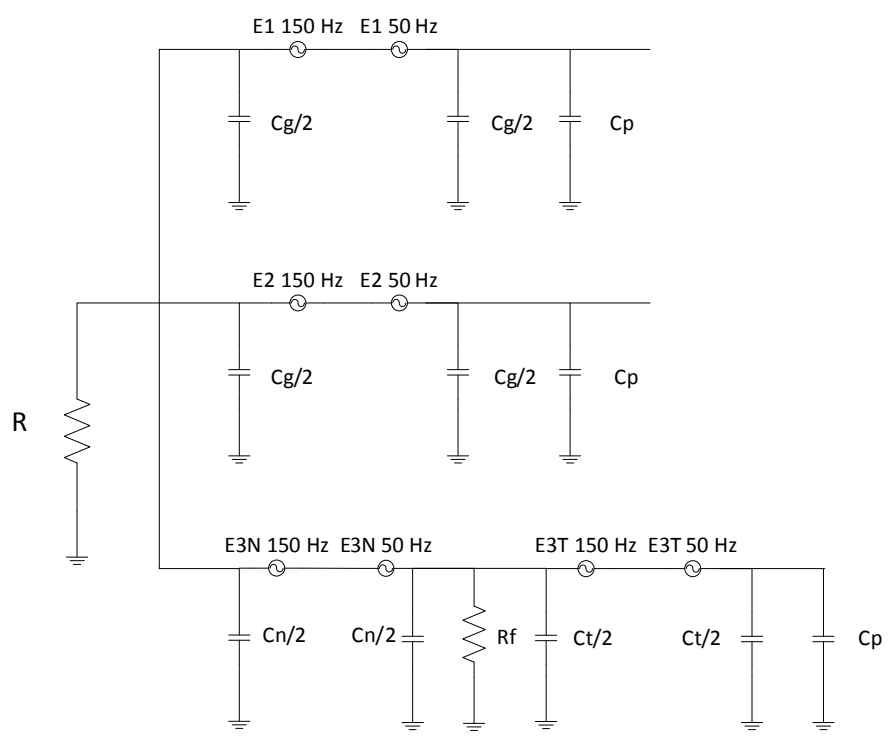

Figure 7. Generator model under fault conditions.

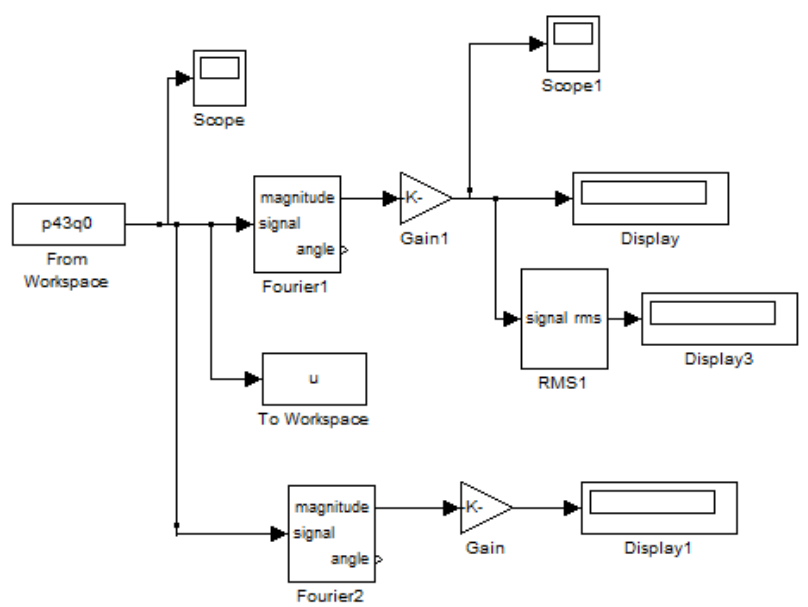

Figure 8. Matlab-Simulink Phase-Neutral Third Harmonic calculation scheme.

The third harmonic of the phase-ground voltage is calculated using Matlab software and then this value should be introduced in the $150 \mathrm{~Hz} \mathrm{AC}$ sources of the generator model under non fault conditions.

If the model is correct, when the value of third harmonic phase-neutral voltage is introduced $\mathrm{U}_{\mathrm{PN}}$, the measurement of third harmonic at the neutral $U_{N G}$ should be a value similar to the one obtained in the measurements.

The other values introduced in the model are the resistance to ground at the neutral, the $50 \mathrm{~Hz}$ AC voltage sources and the capacitance to ground of the generator. 
Numerous cases at different ranges of active and reactive power operation were analyzed.

The influence of the active power is more significant than the reactive power on the results.

There is a resume in the table 2 . In this table are presented the magnitude of the power settings, the third harmonic voltage measurements at the neutral of the 160 MVA generator under study, the $150 \mathrm{~Hz}$ voltage calculated using Matlab-Simulink and finally the third harmonic voltage obtained in the model.

TABLE II. RESUME OF THE CASES ANALYZED UNDER NORMAL OPERATION

\begin{tabular}{|c|c|c|c|c|c|}
\hline $\begin{array}{c}\mathbf{P} \\
{[\mathbf{M W}]}\end{array}$ & $\begin{array}{c}\mathbf{Q} \\
{[\text { Mvar] }}\end{array}$ & $\begin{array}{c}\mathrm{U}_{\mathrm{NG}} \\
150 \mathrm{~Hz} \\
\text { Measured }\end{array}$ & $\begin{array}{c}\mathbf{U}_{\mathbf{P N}} \\
150 \mathrm{~Hz} \\
\text { Calculated }\end{array}$ & $\begin{array}{c}U_{\mathrm{NG}} \\
150 \mathrm{~Hz} \\
\text { Model } \\
\end{array}$ & $\begin{array}{c}\text { Relative } \\
\text { Error } \\
(\%)\end{array}$ \\
\hline 43 & -40 & 124,7 & 146,2 & 129,0 & 3,44 \\
\hline 43 & -30 & 117,8 & 126,2 & 111,3 & 5,50 \\
\hline 43 & -15 & 117,8 & 134,6 & 118,6 & 0,70 \\
\hline 43 & -5 & 124,7 & 145,8 & 128,7 & 3,20 \\
\hline 43 & 0 & 131,6 & 162,4 & 143,2 & 8,79 \\
\hline 43 & 20 & 145,5 & 175,4 & 154,7 & 6,33 \\
\hline 43 & 30 & 152,4 & 156,0 & 137,6 & 9,72 \\
\hline 43 & 40 & 159,3 & 187,6 & 165,4 & 3,80 \\
\hline 43 & 50 & 166,3 & 176,3 & 155,5 & 6,48 \\
\hline 60 & -20 & 152,4 & 171,8 & 151,6 & 0,54 \\
\hline 60 & 10 & 145,5 & 171,8 & 151,6 & 4,20 \\
\hline 60 & 20 & 145,5 & 165,7 & 146,1 & 0,42 \\
\hline 60 & 30 & 152,4 & 160,4 & 141,4 & 7,23 \\
\hline 60 & 40 & 159,3 & 168,9 & 149,0 & 6,49 \\
\hline 70 & -20 & 166,3 & 182,9 & 161,4 & 2,93 \\
\hline 70 & -10 & 159,3 & 164,8 & 145,3 & 8,81 \\
\hline 70 & 0 & 152,4 & 167,7 & 148,0 & 2,90 \\
\hline 70 & 10 & 152,4 & 162,0 & 142,8 & 6,31 \\
\hline 70 & 20 & 159,3 & 189,3 & 166,9 & 4,74 \\
\hline 70 & 30 & 159,3 & 178,9 & 157,8 & 0,97 \\
\hline 70 & 40 & 159,3 & 181,4 & 162,4 & 1,92 \\
\hline 70 & 50 & 159,3 & 181,9 & 160,5 & 0,73 \\
\hline 85 & -10 & 194,0 & 207,0 & 182,5 & 5,92 \\
\hline 85 & -5 & 194,0 & 206,0 & 181,0 & 6,69 \\
\hline 85 & 5 & 180,1 & 192,2 & 169,8 & 5,73 \\
\hline 85 & 10 & 180,1 & 204,2 & 180,1 & 0,02 \\
\hline 85 & 15 & 173,2 & 184,7 & 162,8 & 6,00 \\
\hline 85 & 20 & 173,2 & 184,7 & 162,8 & 6,00 \\
\hline 85 & 25 & 173,2 & 198,8 & 175,4 & 1,27 \\
\hline 85 & 30 & 173,2 & 191,8 & 169,4 & 2,19 \\
\hline
\end{tabular}

The error is also quantified. The uncertainty of the measurements and the fact that all this analysis has been done with a real machine with all that entails, are aspects that are considered during all this studies.

As it can be seen in the table above the relative error is less than the $10 \%$ in any case. With these results at different active and reactive power settings seems reasonable that this model works very similar than the real machine itself. Obviously, there are special situations that are not considered in these type of simulations. Temperature, vibrations, moisture, pressure, etc... All of them affect the measurements and the results obtained.

Considering all the aspects explained above the model presented is verified as a reliable and suitable one for further studies and analysis.

After the first model is valid, the next phase to focus is the verification of the second model referred to the machine when a stator- ground-fault takes place at some point of the winding.

This model is based on the fig. 9 explained in section III.

To tests the validity of the model, certain simulations were procedure. The fault was simulated at different points of the winding, more specifically, from the neutral end to 10 $\%$ of the winding. It is because in this zone is where the overlapping between the under-voltage $27 \mathrm{NTH}$ and the overvoltage $59 \mathrm{~N}$ relays takes place and also this is where current protection system find much more difficulties to stabilize its adjust settings.

As it was explained in the section I of this paper, when a ground fault takes place there are two more parameters to analyze apart from the load and operating conditions. These are the position of the fault and the value of the resistance fault. They affect significantly the magnitude of third harmonic voltage that can be measured at the neutral of one generator.

The main objective of these simulations is to observe the probable behavior of the third harmonic in a real large generator machine at different load situations.

With the taken results, a suitable and better method of adjusting would be considered to develop.

To maintain the same criteria as in the case before, the real and reactive power conditions will be the same as for the non-faulty model,

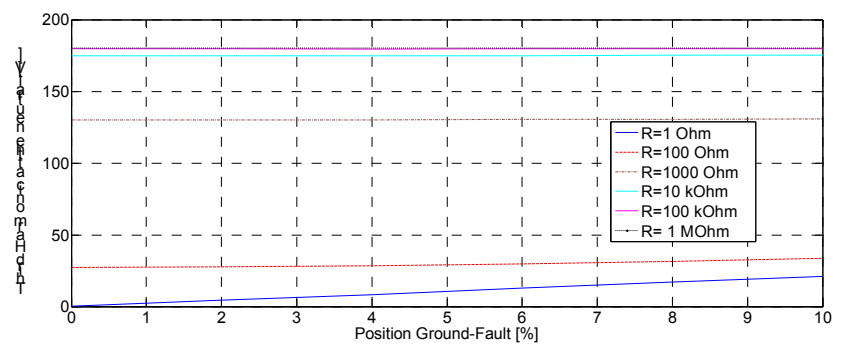

Figure 9. Generator simulation results under fault conditions .

The simulations were made for a fault which took place at the $0,2,4,6,8$ and $10 \%$ of the winding and $0 \Omega, 1 \Omega, 100$ $\Omega, 1 \mathrm{k} \Omega, 100 \mathrm{k} \Omega$, and $1 \mathrm{M} \Omega$ values of fault resistance.

The behavior of the third harmonic voltage was just exactly as it was mentioned at the introduction.

If the fault takes place in a certain point close to neutral point it gets really low. If the fault is even closer to the neutral end gets lower.

Obviously if the defect occurs at a certain point close to the terminals the quantity of third harmonic, we can observe at the neutral is much higher.

If the fault resistance's value is low, the quantity of third harmonic measured at the neutral is also lower. But, if the 
resistance fault has a big value, higher than $10 \mathrm{k} \Omega$, the situation turns like a non-faulty scenario, so the total third harmonic measured at the neutral end is the same as the third harmonic at the neutral in the non-faulty conditions.

This fact is always the same for every different position where the fault takes place.

Another aspect which was also studied is the evolution of the voltage at fundamental frequency.

If the fault was produced at any position in the winding and the fault resistance increases, as the third harmonic increases as well, the $50 \mathrm{~Hz}$ voltage decreases. When we get to that value of the fault resistance where it seems like we are in a non-faulty scenario, the voltage at $50 \mathrm{~Hz}$ decreases to zero as it should be.

These two studies of the voltage at the neutral at $50 \mathrm{~Hz}$ and $150 \mathrm{~Hz}$ are important to develop a method that could set a suitable adjustment for the $100 \%$ ground fault undervoltage $(64 \mathrm{~S})$ and $95 \%$ ground fault over-voltage $(59 \mathrm{~N})$ relays so that the false tripping cases could be avoid.

\section{CONCLUSION}

The third harmonic voltage in the generator depends on the operation conditions. Thanks to the measurement of the voltages phase to ground and neutral to ground, taken in a 106 MVA hydro generator, the third harmonics in the generator windings have been calculated.

From these third harmonics generator voltages in the windings, the model has been validated. After running a simulation, the third harmonic voltage in the grounding resistor obtained was compared to the real measurement. The comparison of the real value and the value from the simulation model gives errors below $10 \%$, which can be considered as acceptable results.

The model could be easily used to simulate internal faults along the generator winding. The results look coherent, but they cannot be compared to real measurement as we do not have ground fault data.

\section{ACKNOWLEDGMENT}

The authors wish to acknowledge the contributions of Mr. Pardo and Mr. Silio of Eon Generación Spain.

\section{REFERENCES}

[1] “IEEE Guide for AC Generator Protection.” IEEE Std C37.102-2006 (Revision of IEEE Std C37.102-1995), pp.1-177, 2006.

[2] "IEEE Guide for the Application of Neutral Grounding in Electrical Utility Systems, Part II-Grounding of Synchronous Generator Systems," IEEE Std C62.92.2-1989.

[3] "IEEE Guide for Generator Ground Protection, "IEEE Std C37. 1012006 (Revision of IEEE Std C37.101-1993/Incorporates IEEE Std C37.101-2006/Cor1:2007), pp. c1-67, Nov. 15, 2007.

[4] Fulcyk, M.; Bertsch, J., "Ground-fault currents in unit-connected generators with different elements groundinng neutral," IEEE Trans. Energy Convers., , vol.17, no.1, pp. 61-66, Mar. .2002..

[5] Pope, J.W., "A comparison of 100 \% Stator Ground Fault Protection Schemes for Generator Stator Windings," IEEE Trans Power Ap. Syst., vol. PAS-103, no. 4, pp. 832-840, Apr. 1984.

[6] Mozina, C.J., "15 years of experience with $100 \%$ generator stator ground faul protection- What works, what doesn't and why," in Proc. IEEE $62^{\text {nd }}$ Annual Conference for Protective Relay Engineers, Mar. 30- Apr.2, 2009, pp. 92-106.

[7] Turner, S., "Applying $10 \%$ stator ground fault protection by low frequency injection for generators," in Proc. IEEE PES Power \& Energy Society Generaal Meeting, July 26-30, 2009, pp. 1-6.

[8] Sclake, R.L.; Buckley, G. W.; McPherson, G., "Performance of Third Harmonic Ground Fault Protection Schemes for Generator Stator Windings," IEEE Trans Power Ap. Syst., vol.PAS-100, no. 7, pp. 3195-3202, July 1981.

[9] Fulczyk, M.; Mydlikowski, R., "Influence of generator load conditions on third-harmonic voltages in generator stator winding," IEEE Trans. Energy Convers., vol. 20, no. 1, pp. 158-165, Mar. 2005.

[10] Zielichowski, M.; Fulczyk, M., "Analysis of operatting conditions of ground-fault prrotection schemes forr generator stator winding," IEEE Trans. Energy Convers., vol. 18, no. 1, pp. 57-62, Marr. 2003.

[11] Fulczyk, M., "Voltage $3^{\text {rd }}$ harmonnic in generator stator winding at changes in generator load conditions," in Proc. IEEE IEMDC'03, June1-4, 2003, vol.3, pp. 1476-1482.

[12] Lloyd, G.J. Yiip, H. T.; Millar, G., "Operation, Design and Testing of Generator 100 \% Statir Earth Fault Protection Using Low Frequency Injection," in Proc. IET DPSP, Mar. 17-20, 2008, 99. 92-97. 